\title{
Evaluation of the role of rock properties in the development of potholes: A case study of the Indrayani knickpoint, Maharashtra
}

\author{
Somasis Sengupta* and Vishwas S Kale \\ Department of Geography, University of Pune, Pune 4110\%, India. \\ *e-mail: somasis_22@rediffmail.com
}

The most conspicuous erosional features associated with constricted bedrock channel reaches and knickpoints are potholes. The presence and morphology of potholes have been attributed to a number of factors by earlier researchers. Amongst these factors, the role of substrate rock properties has received very little quantitative attention. The main objective of this study is to quantitatively evaluate the physical properties of bedrock in order to test the possible influences of rock properties on the occurrence and morphology of potholes. The area selected for this study is a large scabland area developed by the Indrayani river at Shelarwadi near Pune. This site is ideally suited for the study since it is featured by wide straths, multiple inner channels and several hundred potholes. A transect-based quadrat method was used in this study. Within each quadrat, the pothole dimensions, the joint length, joint direction, the rock mass strength and the distance from active channel were measured. The analysis reveals a weak correlation between pothole size and rock properties. The distance from the active channel emerges as the most significant factor, suggesting that the hydraulics of flows is the key factor and substrate characteristics play only a secondary role.

\section{Introduction}

Potholes are meso-scale erosional landforms (cm-m scale) and are observed in a wide range of climates, lithologies and channel types (Wohl 1998). These circular or oval-shaped depressions in rocks formed by fluvial corrasion, abrasion and cavitation are usually associated with bedrock reaches of rapid flow (Wohl 1998; Kale and Gupta 2001). It is now well-recognized that the most effective way of erosion and incision in bedrock is via potholes (Wohl 1998). Therefore, potholes are important components of channel incision and are responsible for the distinctive appearance of bedrock channels (Kale and Shingade 1987; Springer et al 2006). According to Kale and Shingade (1987), these features are initiated as small pits or depressions, mostly along joints and fractures. The tiny depressions trap more water and sediments, promoting localized erosion through whirling motion. As a result, the depression is further abraded, deepened and widened, forming typical potholes. These potholes gradually enlarge and coalesce eventually to give rise to inner channels.

The occurrence, morphology, density and distribution of potholes along bedrock channel reaches have been attributed to a number of factors, such as substrate characteristics (joint density and orientation, rock hardness, etc.), hydraulics of flow (velocity, turbulence, magnitude, shear stress, etc.),

Keywords. Pothole; knickpoint; joint density; rock mass strength; Schmidt rock hammer. 


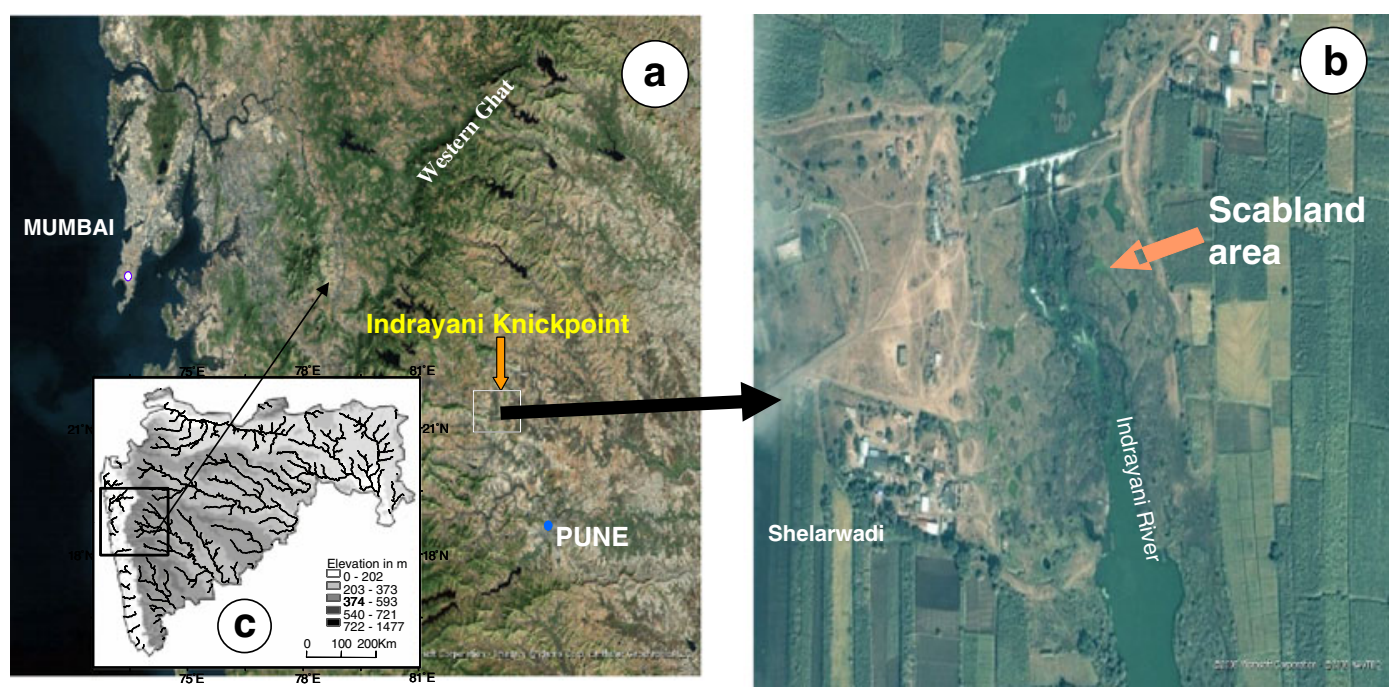

Figure 1. (a) Satellite image of western Maharshtra. (b) GoogleEarth image of the Indrayani knickpoint. Flow is from north to south. (c) DEM of Maharshtra.

availability of abrasive material, etc. (Wohl 1992; Lorenc et al 1994; Wohl 1998; Springer et al 2006; Wang et al 2009). Amongst these factors, the role of physical properties of bedrock in the development and evolution of potholes has received very little quantitative attention. The main objective of the present paper, therefore, is to ascertain whether the physical properties of bedrock have any control on pothole morphology and development. The area selected for the study is a large scabland area developed by the Indrayani river in the upper Bhima Basin.

\section{The study site}

With an area of about $995 \mathrm{~km}^{2}$ and channel length of $104 \mathrm{~km}$, the Indrayani river is one of the major tributaries of the Bhima river. The river rises in the high-rainfall zone (4500-5000 $\mathrm{mm}$ ) of the Western Ghat, near Lonavala town, and flows through the rainshadow zone before draining into the Bhima river. In general, the channel of the Indrayani river is incised in bedrock basalt throughout its course.

In its lower reach, strong non-equilibrium conditions of the river are reflected by the presence of a prominent knickpoint at Shelarwadi $\left(18^{\circ} 42^{\prime} \mathrm{N}\right.$ and $73^{\circ} 42^{\prime} \mathrm{E}$ ) near Pune (figure 2a). The prominent topographic feature is characterized by a wide scabland $\left(56,700 \mathrm{~m}^{2}\right)$ with multiple inner channels, wide straths on both sides of the active channel and over 600 potholes (Kale and Shingade 1987; Kale and Joshi 2004). The scabland topography (figure 1 ) is developed entirely in compound lava flows with amygdaloidal characters. Joints and fractures within the flows are common and most often
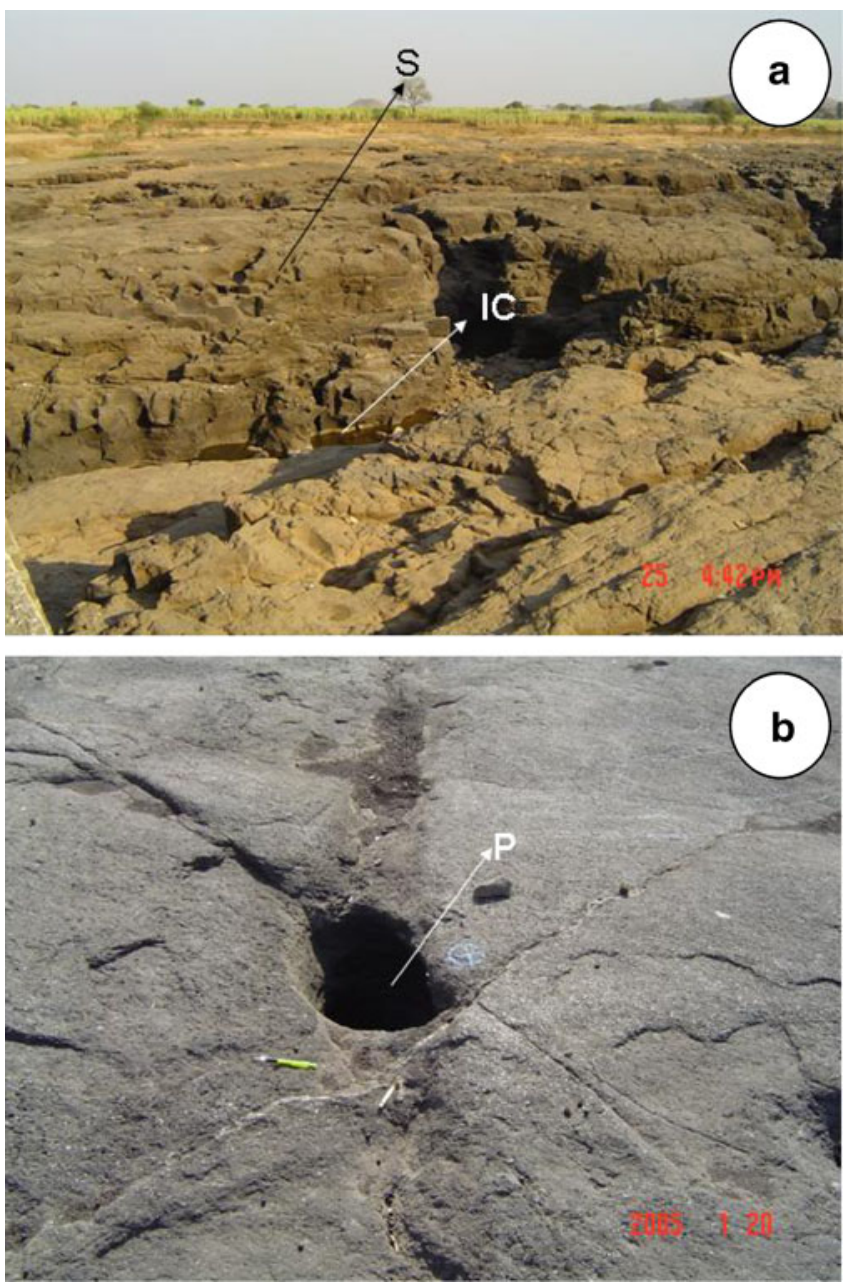

Figure 2. (a) A view of the scabland area developed by the Indrayani river at Shelarwadi. S: strath, IC: inner channel. (b) An isolated pothole $(\mathrm{P})$ developed at a joint intersection in compound lava. 


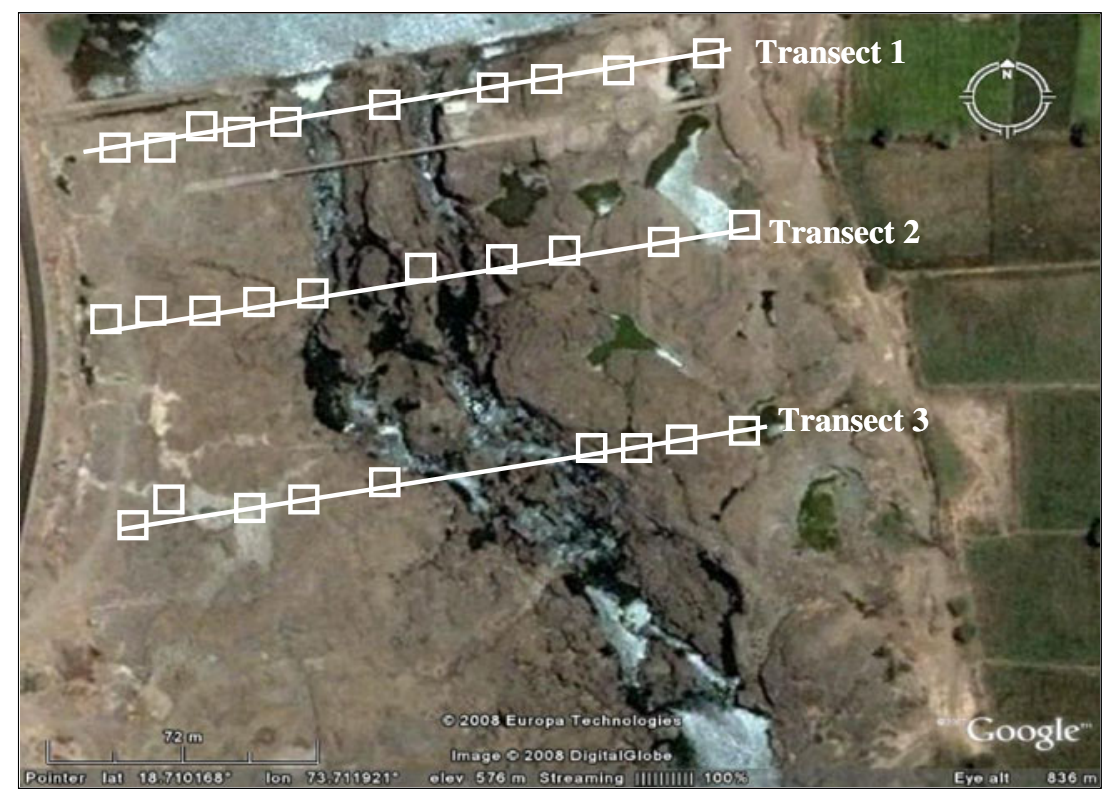

Figure 3. GoogleEarth image of the Indrayani knickpoint (study area) showing the location of the transect lines and the quadrats (represented by white squares). The black square represents approximately the location and extent of the man-made quarry. KP: knickpoint.

potholes occur at the intersection of joints (figure $2 \mathrm{~b})$ or along joints.

Although coarse gravel and sand is observed within some potholes, there is near-complete absence of alluvial cover over the scabland area, implying that the river is not transport-limited and tool effect dominates (Turowski et al 2008). Evidently, the Indrayani scabland is an area of high concentration of energy dissipation and active fluvial erosion and bedrock incision. Kale and Joshi (2004) have reported evidence of formation for several potholes on human timescale $(<60 \mathrm{yrs}$ ) from the site under review.

\section{Methodology}

In the current study, a transect-cum-quadrat method was used. Three transect lines were laid across the scabland area - one upstream, one downstream and one in the middle (figure 3). Each transect line extended from the left bank to the right bank of the river was oriented roughly perpendicular to the flow direction. About 9-10 quadrats of $3 \times 3 \mathrm{~m}$ were laid roughly along each transect line (figure 3). Each quadrat was further subdivided into nine sub-quadrats, each $1 \times 1 \mathrm{~m}$ in size.

In order to quantify the pothole size and shape, the depth and length of all the potholes within each quadrat were measured. The length was measured because most of the potholes are not perfectly circular but oval in shape. The long axis was also used to determine the general orientation of the potholes for comparison with the orientation of joints in underlying basalts. The average pothole length and depth were calculated by dividing the total length and total depth of all the potholes by the quadrat area $\left(9 \mathrm{~m}^{2}\right)$.

The substrate rock characteristics were evaluated in terms of the joint density and rock mass strength. The joints were classified in the field as minor, major and prominent on the basis of their length, width, continuity and prominence for each sub-quadrat. The joint density was estimated for each quadrat by taking the ratio between the total length (sum of all sub-quadrats) and the area of the quadrat $\left(9 \mathrm{~m}^{2}\right)$. A clinometric compass was used to measure the orientation of all the joints as well as the average slope of the quadrat.

Estimation of the strength of the in situ rock within the quadrat was obtained using an 'N-type' Schmidt rock hammer, which measures the distance of rebound of a controlled impact on a surface and represents a relative measure of surface hardness or strength (Goudie 2006). The impact readings were taken at the corner of each subquadrate. Thus, in all 16 readings for each quadrat were obtained. Following the standard procedure, the impact readings were converted into standard averages of resistance (in $\mathrm{N} / \mathrm{mm}^{2}$ ) by calculating a statistical power-law relationship (Goudie 2006). The following conversion curve was used:

$$
\mathrm{RMS}=0.1152 \mathrm{~N}^{1.6348},
$$

where RMS is the rock resistance or rock mass strength in $\mathrm{N} / \mathrm{mm}^{2}$ and $\mathrm{N}$ is the Schmidt rock hammer rebound value. The RMS values obtained for 
Table 1. Transectwise variations in average pothole length and depth.

\begin{tabular}{|c|c|c|c|c|c|c|}
\hline Transect line number & Maximum & Minimum & Range & Mean & $\begin{array}{l}\text { Standard } \\
\text { deviation }\end{array}$ & $\begin{array}{l}\mathrm{CV} \\
(\%)\end{array}$ \\
\hline \multicolumn{7}{|l|}{ Average length in $\mathrm{cm}$} \\
\hline 1 & 40.56 & 7.78 & 32.78 & 30.15 & 17.53 & 58.14 \\
\hline 2 & 63.22 & 11.11 & 52.11 & 37.97 & 17.99 & 47.38 \\
\hline 3 & 64.89 & 20.89 & 44.00 & 42.65 & 16.01 & 37.54 \\
\hline \multicolumn{7}{|l|}{ Average depth in $\mathrm{cm}$} \\
\hline 1 & 32.78 & 5.56 & 27.22 & 13.21 & 9.14 & 69.19 \\
\hline 2 & 32.78 & 5.56 & 27.22 & 18.72 & 10.51 & 56.14 \\
\hline 3 & 92.22 & 9.28 & 82.94 & 38.97 & 30.52 & 78.32 \\
\hline
\end{tabular}

$\mathrm{CV}$ is the coefficient of variation.

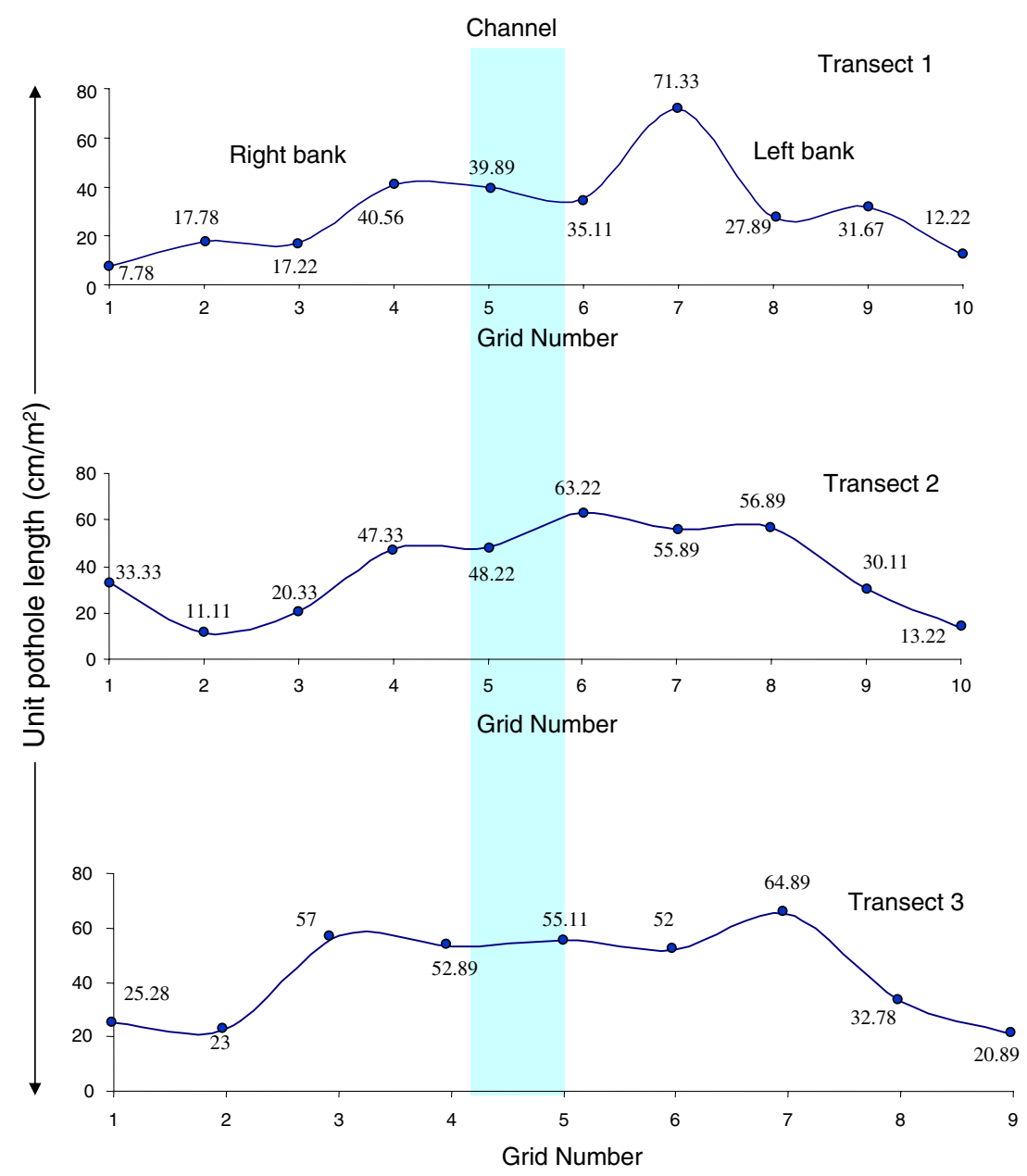

Figure 4. Graph for quadrat-wise variation in average pothole lengths across all transect lines.

the 16 Schmidt hammer readings were averaged in order to get the mean rock resistance of the quadrat.

Data on flow dynamics and sediment transport (suspended or bedload) are completely lacking for the site as well as for the entire river. However, it must be noted that the studied site in question is a deep and narrow channel as revealed by an
EDM total station survey (Kale and Joshi 2004). In the absence of flow hydraulic data, the distance from the active channel was considered as a surrogate for the total energy expenditure. This is because, in deep and narrow bedrock channels at high flow stage the width-depth ratio is low and the maximum shear stress and velocity gradient is large towards the banks (Turowski et al 2008). 


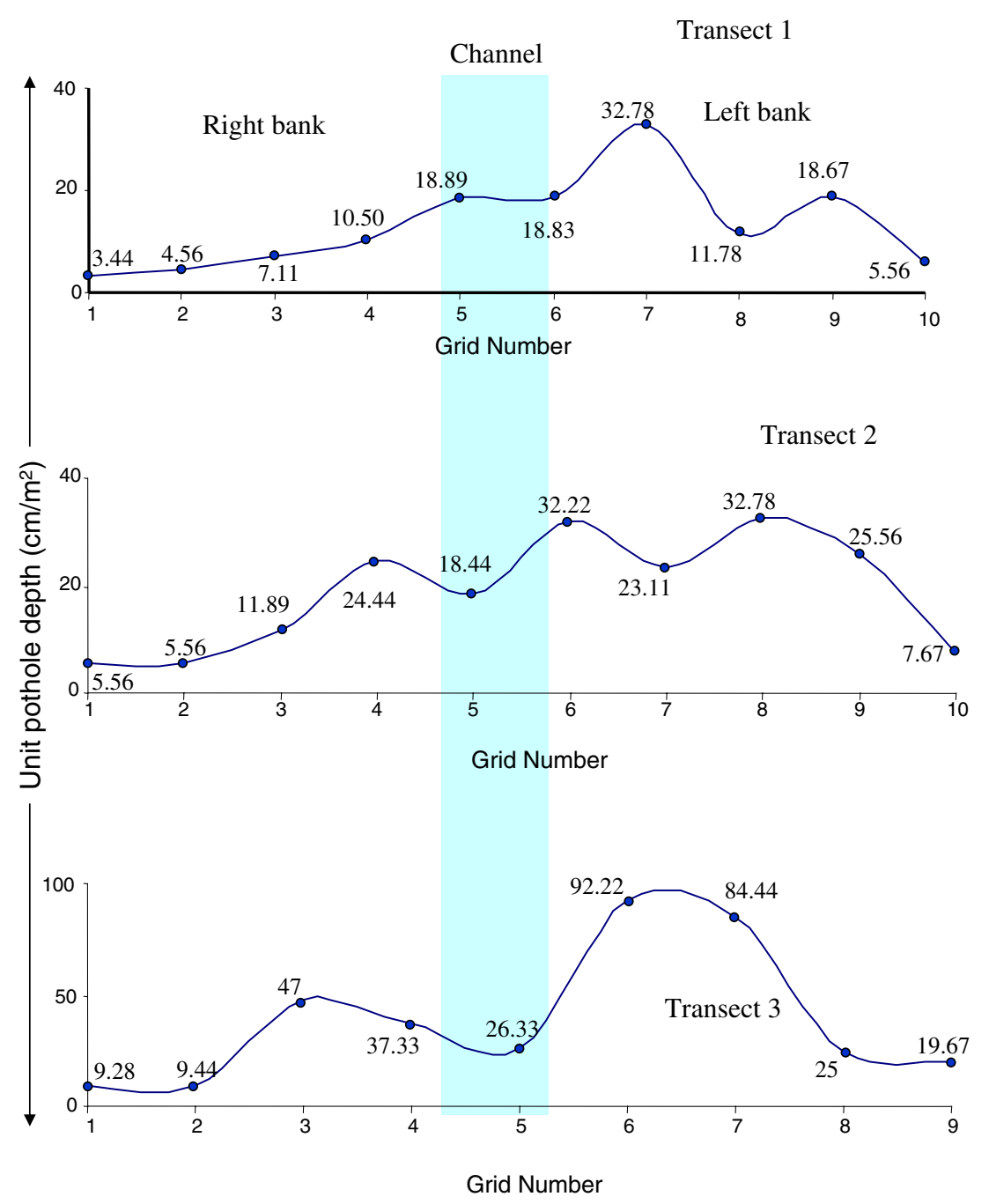

Figure 5. Line plot showing the intra-transect differences in the average pothole depth across all transect lines.

Table 2. Bivariate correlations of pothole length and depth verses other rock properties.

\begin{tabular}{lcccccc}
\hline Attribute & PL & PJ & MJ & RMS & $D$ & $S$ \\
\hline PL & 1.00 & 0.12 & 0.10 & -0.074 & $-0.66^{*}$ & 0.13 \\
PD & 1.00 & 0.002 & 0.19 & -0.16 & $-0.52^{*}$ & 0.13 \\
\hline
\end{tabular}

Note: PL is the average pothole length, PD the average pothole depth, PJ the major joint density, MJ the minor joint density, RMS the rock resistance, $D$ the distance from the channel and $S$ is the slope of the quadrat. * Significant at 0.01 level.

Consequently, more fluvial erosion and abrasion is expected closer to the banks during high monsoon flows, rather than away from the bank.

\section{Results}

\subsection{Longitudinal and lateral variations in pothole morphology}

The average lengths and depths of potholes for each transect line are given in table 1 . The summary statistics reveals that as one moves downstream, the average length as well as the depth of the potholes increase. This is expected, because knickpoints recede upstream and erosion is always at an advanced stage downstream. However, the ANOVA test indicates that this trend is statistically significant only for average depth. Further, the average pothole length increases away from the active channel (figure 4). Similar trend is depicted by average pothole depth (figure 5). Bivariate correlation between pothole morphological properties and the distance from the channel reveals significant relationships (table 2). 
Table 3. Transectwise differences in joint density $\left(\mathrm{cm} / \mathrm{m}^{2}\right)$ for each type of joint

\begin{tabular}{lcccccr}
\hline Joint type & $\begin{array}{c}\text { Transect } \\
\text { line number }\end{array}$ & Maximum & Minimum & Range & Mean & $\begin{array}{r}\text { Standard } \\
\text { deviation }\end{array}$ \\
\hline Minor & 1 & 75.67 & 12.11 & 63.56 & 44.94 & 19.93 \\
& 2 & 63.56 & 34.67 & 28.89 & 47.3 & 8.38 \\
\multirow{2}{*}{ Major } & 3 & 69.11 & 38.33 & 30.78 & 54.31 & 10.57 \\
& 1 & 163.89 & 0 & 163.89 & 85.10 & 55.63 \\
\multirow{3}{*}{ Prominent } & 2 & 147.22 & 38 & 109.22 & 87.73 & 35.07 \\
& 3 & 144.33 & 23.75 & 120.55 & 93.33 & 39.44 \\
& 1 & 12.67 & 0 & 12.67 & 4.86 & 5.06 \\
& 2 & 16.11 & 0 & 16.11 & 4.06 & 5.66 \\
& 3 & 25.44 & 0 & 25.44 & 5.30 & 9.94 \\
\hline
\end{tabular}

Channel

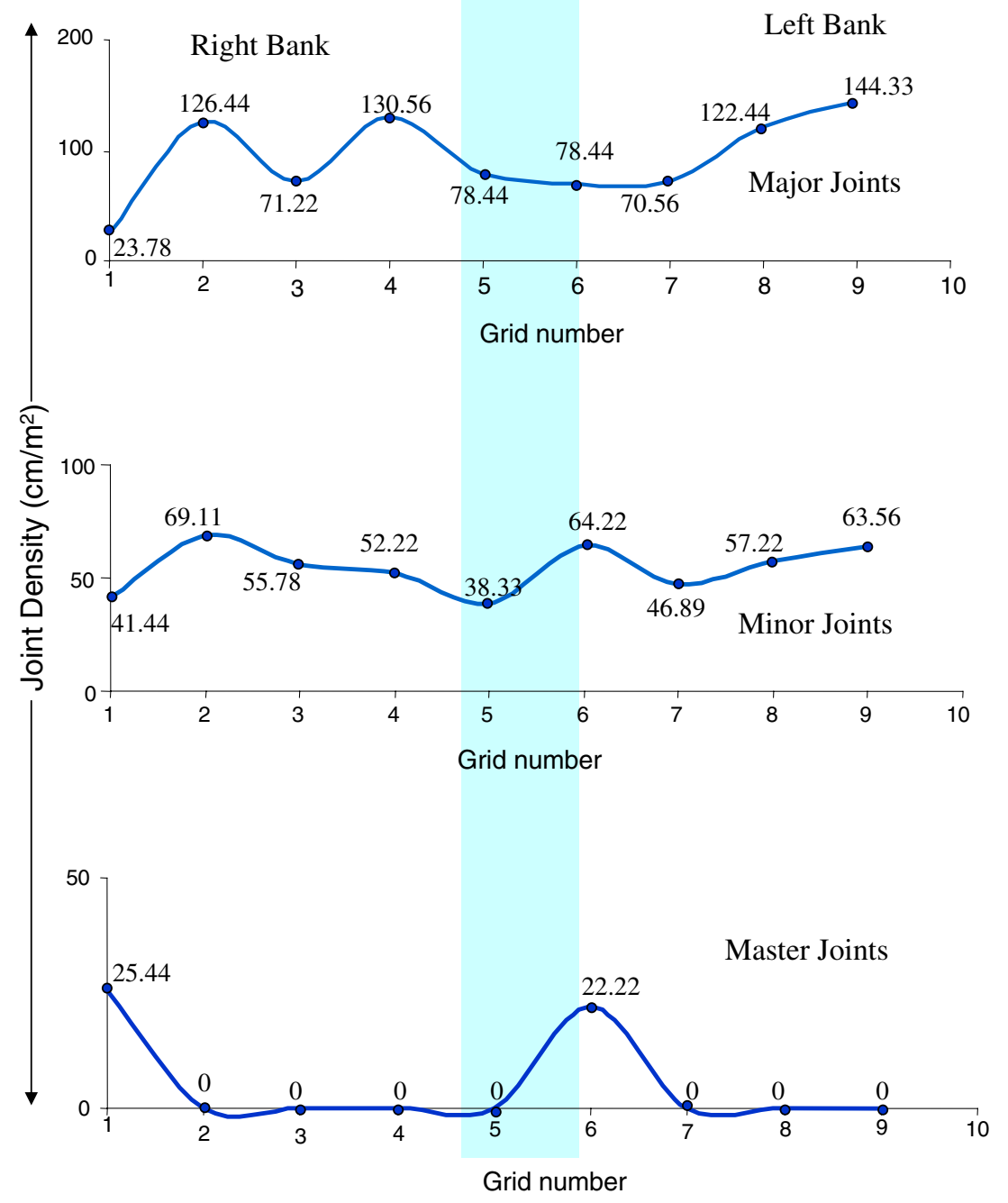

Figure 6. Lateral variations in the densities of different types of joints for transect line 3. Similar results were obtained for transect lines 1 and 2 . Only the data for transect line 3 is presented here.

\subsection{Substrate rock properties}

The data presented in table 3 illustrates that, in general, the average joint density slightly increases downstream. However, the results are not statistically significant as per the ANOVA test. The joint density also does not show any across-transect pattern of variation (figure 6). 


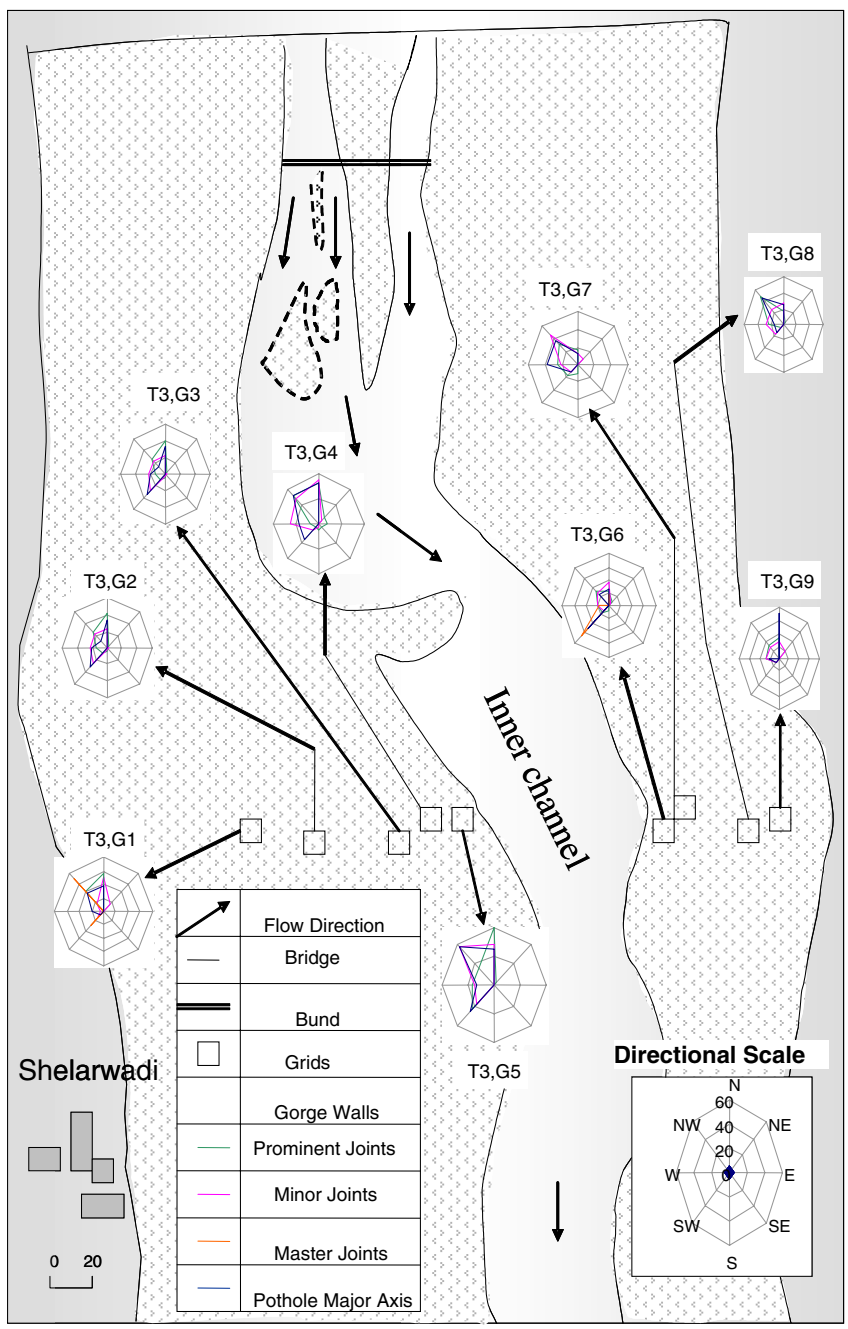

Figure 7. Gradient rose diagram showing the orientation of different types of joints and the major axis of the potholes for transect line number 3 . This is a representative of all the three transect lines since transect lines 1 and 2 have yielded similar results.

The alignments of all the three types of joints were compared with each other as well as with the major axis of the potholes by plotting the data on the rose or radar diagram for each quadrat. The rose diagrams for transect line number 3 are given in figure 7 for illustration. Examination of the plots demonstrates a slightly better relationship between the pothole length and only the major joints. It is pertinent to mention here that the dominant direction of the major joints is approximately north-south, which is also roughly in accordance with the direction of the main channel.

The rock mass strength varies spatially, but does not show any specific pattern or trend in surface hardness (table 4 and figure 8). The only noteworthy point is that the mean resistance of the second transect line is slightly higher, perhaps because fresh rock is exposed by excavation on the right bank (figure 2).

\subsection{Control of rock properties on pothole morphology}

In order to statistically evaluate the relationship between the pothole dimensions and the measured controlling factors, correlation analysis was carried out. The correlation values given in table 2 indicate a perfect positive relationship between the average pothole depth and length. This simply implies that as the size of the pothole increases the depth also increases proportionally.

With respect to other parameters, the distance from the channel emerges as the most significant factor determining the pothole size. The negative correlation suggests that as one moves away from the active channel, the potholes become smaller and shallower. The distance factor, however, explains only $43 \%$ of the variance in pothole length and $27 \%$ variance in pothole depth.

The low explained variances perhaps imply that the distance factors in combination with physical properties of rocks, rather than independently, may be exerting a strong control on the pothole morphology and occurrence. Therefore, to establish the relationship between pothole morphologic properties on the one hand and the selected parameters on the other, multiple regression analysis was carried out. The following relationships were derived:

$$
\begin{aligned}
\mathrm{PL}= & 72.05+0.04 \mathrm{MAXJ}-0.24 \text { MINJ } \\
& -0.60 \mathrm{RMS}-0.79 \mathrm{D} \\
& +280.91 S\left(R^{2}=0.62\right), \\
\mathrm{PD}= & 49.91-0.16 \mathrm{MAXJ}+0.58 \mathrm{MINJ} \\
& -0.0 .95 \mathrm{RMS}-0.70 D \\
& +205.48 S\left(R^{2}=0.49\right),
\end{aligned}
$$

where $\mathrm{PL}$ is the average pothole length in $\mathrm{cm}, \mathrm{PD}$ the average pothole depth in $\mathrm{cm}$, MAXJ the major joint density in $\mathrm{cm} / \mathrm{m}^{2}$, MINJ the minor joint density in $\mathrm{cm} / \mathrm{m}^{2}$, RMS the rock mass strength in $\mathrm{N} / \mathrm{mm}^{2}, D$ the distance from the channel in $\mathrm{m}$ and $S$ the average slope of the quadrat in $\mathrm{m} / \mathrm{m}$.

The multiple correlation values indicate that about two-thirds variance in pothole length and about one-half variance in pothole depth and is explained by the above-mentioned factors. Other factors that could not be quantified are hydrodynamics of monsoon flows, bed shear stress, flow turbulence, the amount and size of abrasive materials, etc. which perhaps account for the remaining variance. 
Table 4. Rock mass strength (in $\mathrm{N} / \mathrm{mm}^{2}$ ) variations between the transect lines

\begin{tabular}{ccccccc}
\hline $\begin{array}{c}\text { Transect } \\
\text { line number }\end{array}$ & Maximum & Minimum & Range & Mean & $\begin{array}{c}\text { Standard } \\
\text { deviation }\end{array}$ & $\begin{array}{c}\text { CV } \\
(\%)\end{array}$ \\
\hline 1 & 40.82 & 20.56 & 20.26 & 32.80 & 5.61 & 17.10 \\
2 & 57.38 & 26.69 & 30.69 & 35.33 & 11.26 & 31.87 \\
3 & 35.94 & 26.69 & 9.25 & 31.61 & 3.41 & 10.79 \\
\hline
\end{tabular}

$\mathrm{CV}$ is the coefficient of variation.

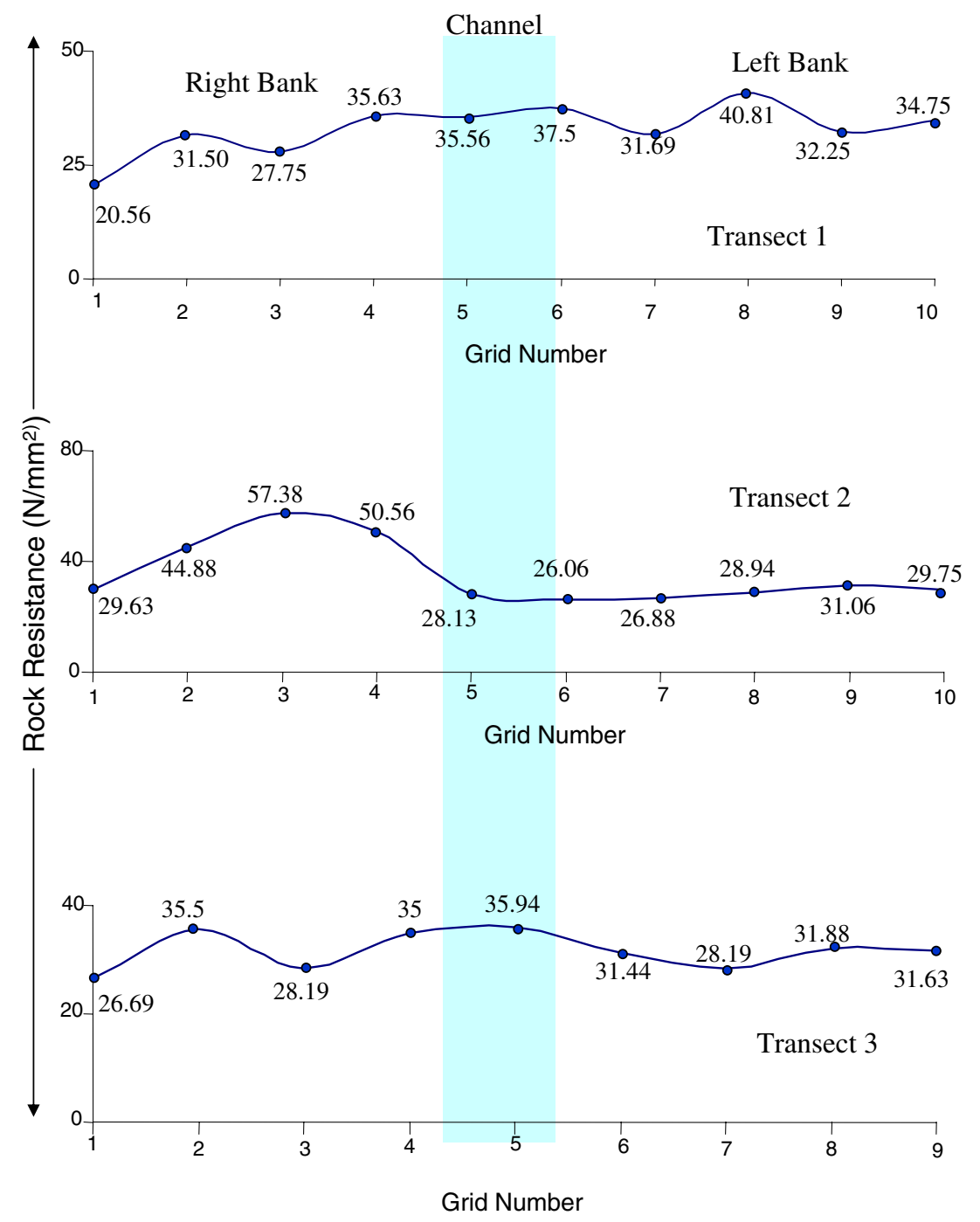

Figure 8. Line graph showing the lateral variation in rock resistance across all the transect lines.

\section{Discussion and conclusions}

Knickpoints are non-equilibrium landforms and occur as major breaks in the longitudinal profile of a river. These are undoubtedly the sites of high energy expenditure. The energy is utilized to erode the bedrock and transport the sediments imposed from upstream. The occurrence of multiple erosional features, such as potholes, grooves, inner channels, etc. at the Shelarwadi site indicates that maximum energy is being expended, particularly close to the active channel, where flow depth and velocity are high during monsoon floods. Although corrasion is largely the function of the hydraulics of flows and the amount and nature of abrasive material, it also depends to a considerable extent on the erosional resistance of rock (Wohl 1998). It has been suggested and demonstrated that the distinctive bedrock channel morphology results from a complex adjustment between hydraulics and substrate characteristics (Wohl and Merritt 2001). The substrate characteristics (such as composition, 
hardness, structural discontinuity, etc.) determine rock erodibility and its rate. The main objective of this study was to quantitatively evaluate the physical properties of bedrock in order to test the possible influences of the rock properties on the occurrence and morphology of potholes.

The data generated during this study indicates that the orientation of the potholes is to some extent related to the orientation of joints, particularly the major joints. It appears that the flows display a tendency to exploit the zones of weakness (joints and fracture) to initiate erosion in bedrock. The abrasive material moving as bedload or suspended load is drawn to the pits and depressions are created along the joint. Further erosion of pits and depressions gives rise to potholes.

The modest relationship between the rock mass strength and the morphological properties of potholes suggests that this factor may not be the most critical factor determining the presence and morphology of potholes in this area of more or less uniform lithology and high-energy expenditure. This observation is further supported by a strong relationship between distance from the inner channels and the pothole dimensions. The fact that majority of the bigger and coalesced potholes characteristically occur close to the constricted inner channels, and that the length and depth of the potholes decrease away from the channel indicates the dominance of hydraulic controls. Many earlier researchers have suggested that high-magnitude flows are critical in shaping bedrock channels and associated erosional features, because only such flows are capable of exceeding the high boundary resistance provided by bedrock channels (Baker and Kale 1998). The average values of the rock mass strength at the study site is in the range of $30-35 \mathrm{~N} / \mathrm{mm}^{2}$. Such high resistance can be exceeded only during exceptionally by large flows, which occur at long intervals.

Another plausible explanation that could account for higher erosion close to the active channel is the influence of internal rock moisture content during monsoon season. Experimental studies by Sumner and Nel (2002) have shown that the Schmidt hammer rebound values (and the rock mass strength) for samples of basalt and other rocks decrease with increasing moisture content. Therefore, it appears that increase in internal rock moisture content along the banks during the monsoon season and occurrence of large-magnitude floods within the same period enable the flows to exceed the rock resistance and erode the bedrock more effectively via potholes.
This study underscores the dominant role played by hydraulics of flows and the over-the-rock resistance in the erosion and incision of bedrock basalt. The main conclusion that emerges is that the ability of a stream to erode in bedrock is largely governed by the channel gradient (which determines the velocity and shear stress) and the amount of abrasive material rather than physical properties of rocks, especially in an area of uniform lithology. It is pertinent to mention here that the results obtained from the current study cannot be extended towards basins or sites underlain by multiple lithologies as it is expected that such an area will yield higher variabilities in the rock mass strengths.

\section{References}

Baker V R and Kale V S 1998 The role of extreme floods in shaping bedrock channels; Rivers Over Rock: Fluvial Processes in Bedrock Channels, Geophysical Monograph (Washington D.C.: American Geophysical Union) pp. $153-164$.

Goudie A 2006 The Schmidt hammer in geomorphological research; Prog. Phys. Geogr. 30 703-718.

Kale V S and Gupta A 2001 Introduction to geomorphology (Kolkata: Orient Longman).

Kale V S and Joshi V U 2004 Evidence of formation of potholes in bedrock on human time-scale: Indrayani River, Pune District, Maharashtra; Curr. Sci. 86 723726.

Kale V S and Shingade B S 1987 A morphological study of potholes of Indrayani knick-point (Maharashtra); Explorations in Tropics (eds) Datye V S et al, Dr Dikshit Felicitation Volume, Pune, pp. 206-214.

Lorenc M W, Barco P M and Saavedra J 1994 The evolution of potholes in granite bedrock, West Spain; Catena 22 $265-274$.

Sumner P and Nel W 2002 The effect of rock moisture on Schmidt hammer rebound: Tests on rock samples from Marion Island and South Africa; Earth Surf. Proc. Land. 27 1137-1142.

Springer G S, Tooth S and Wohl E E 2006 Theoretical modeling of stream potholes based upon empirical observations from the Orange River, Republic of South Africa; Geomorphology 82 160-176.

Turowski J M, Hovius N, Meng-Long H, Lague D and MenChiang C 2008 Distribution of erosion across bedrock channels; Earth Surf. Proc. Land. 33 353-363.

Wang W, Liang M and Huang S 2009 Formation and development of stream potholes in a gorge in Guangdong; J. Geogr. Sci. 19 118-128.

Wohl E E 1992 Bedrock benches and boulder bars: Floods in the Burdekin Gorge of Australia; Geol. Soc. Am. Bull. 104 770-778.

Wohl E E 1998 Bedrock channel morphology in relation to erosional processes; In: Rivers Over Rock: Fluvial Processes in Bedrock channels (eds) Tinkler K J and Wohl E (Washington D.C.: American Geophysical Union) pp. 133-151.

Wohl E E and Merritt D M 2001 Bedrock channel morphology; Geol. Soc. Am. Bull. 113 1205-1212. 